InterAção | 259

\title{
COALIZÕES HORIZONTAIS NO MARCO SUL-SUL: REFLEXÕES SOBRE ESPAÇOS ESTRATÉGICOS DE COOPERAÇÃO
}

\author{
Cristine Koehler Zanella ${ }^{1}$ \\ Eduardo Ernesto Filippi
}

\section{Resumo}

Considerando a configuração das relações horizontais do tipo Sul-Sul implementadas a partir da década passada, o presente artigo procura contribuir para delimitar questões terminológicas e conceituais bem como para refletir sobre a possibilidade de instrumentalização da cooperação para o alcance de diversos fins.

1 Doutoranda do Programa de Pós-Graduação em Estudos Estratégicos Internacionais da Universidade Federal do Rio Grande do Sul (UFRGS). Mestre em Integração Latino-Americana (área de concentração: Direito da Integração) pela Universidade Federal de Santa Maria (UFSM) e graduada em Direito e em Ciências Econômicas pela mesma instituição. Professora do Centro Universitário Ritter dos Reis, em Porto Alegre, e da Faculdade de Direito de Santa Maria, em Santa Maria. Membro do Núcleo de Pesquisas em Relações Internacionais de Santa Maria (PRISMA), no eixo Integração Regional e Globalização. E-mail: criskz.sma@gmail.com 2 Doutor em Economia Política (Université de Versailles - Saint-Quentin-en-Yvelines, França), Mestre em Economia Rural (UFRGS) e Bacharel em Ciências Econômicas (UFRGS). Professor Adjunto do Departamento de Ciências Econômicas da UFRGS, no qual ministra disciplinas para os cursos de Economia e de Relações Internacionais. Professor e pesquisador nos Programas de Pós-Graduação em Estudos Estratégicos Internacionais (PPGEEI) e em Desenvolvimento Rural (PGDR). Professor colaborador no Doutorado em Ciências Sociais da UNI-CV (Cabo Verde) e nos Programas de Pós-Graduação em Economia da UFRR (Boa Vista, RR) e da UEMS (Dourados, MS). E-mail: edu_292000@yahoo.com.br 
Passa-se, então a considerar aspectos necessários à implementação da Cooperação Sul-Sul relativos a atores, setores e instrumentos e, por fim, procura-se desenhar um quadro de oportunidades e desafios que os países do Sul precisam considerar ao lançarem-se nas iniciativas desta natureza.

Palavras- chave: Cooperação Sul-Sul. Coalizões horizontais. Multilateralismo. Parcerias estratégicas internacionais.

\section{Abstract}

Considering the configuration of the South-South horizontal relations implemented over the past decade, this article aims to contribute to define the terminology and conceptual issues and to reflect on the possibility of the cooperation's instrumentalization. It addresses elements regarding actors, sectors and instruments necessary to implement the South-South Cooperation and finally, seeks to draw a picture of opportunities and challenges that South countries need to consider if they intend to embark on such initiatives .

Keywords: South-South Cooperation. Horizontal coalitions. Multilateralism. International strategic partnerships.

\section{INTRODUÇÃO}

Grande parte dos países reunidos no movimento do Terceiro Mundo, que emergiu e floresceu entre as décadas de 60 e 70, passou 
pela última década do século passado lutando contra crises econômicas e sociais que afloraram na década de 80. Após o intenso percurso do século anterior, esses países entraram no século XXI procurando resolver problemas estruturais de desenvolvimento interno ao mesmo tempo em que buscavam novas alternativas ao unilateralismo global da potência estadunidense que emergiu do pós-Guerra Fria.

Esses países, agregados em sua maioria na categoria do Sul econômico - em uma associação em grande medida correspondente com suas localizações geográficas -, há alguns anos vem experimentando novos concertos entre si, em uma cooperação horizontal a que se convencionou chamar de Cooperação Sul-Sul (CSS).

Apesar das iniciativas se darem em várias frentes, em formatos mais ou menos institucionalizados, e de existir farto material indicando atividades dentro do marco Sul-Sul de cooperação, há pouca elaboração teórica que subsidie uma reflexão mais sistematizada sobre essas relações.

Nesse contexto, o presente artigo procurará contribuir para enfrentar esse déficit a partir da abordagem de alguns questionamentos atuais relativos à CSS no que se refere à pertinência de sua terminologia à possibilidade de instrumentalização da cooperação para o alcance de diversos fins. Tendo em vista a reflexão das seções anteriores, propõe-se uma conceituação para esta forma específica de cooperação horizontal. Passa-se, então a considerar aspectos necessários à implementação da CSS relativos a atores, setores e instrumentos e, por fim, procura-se desenhar um quadro de oportunidades e desafios que os países do Sul precisam considerar ao lançarem-se nas iniciativas dessa natureza. 


\section{Questões terminológicas}

Dois questionamentos são frequentemente levantados em relação à CSS no que se refere à sua terminologia.

$\mathrm{O}$ primeiro diz respeito à divisão Norte-Sul da qual o termo parte. A clássica separação a partir de uma linha sinuosa em que os países desenvolvidos se localizam ao norte (mais a Austrália ao sul) e os subdesenvolvidos ao sul do mapa mundial (conforme Figura 1) provoca contestações a respeito dessa classificação que enquadra os segundos em uma condição de dependência em relação aos primeiros. Tais contestações são propugnadas especialmente com relação à dificuldade de classificação de países que atualmente apresentam padrões de crescimento econômico consideráveis, tais como a China, o Brasil e a Índia.

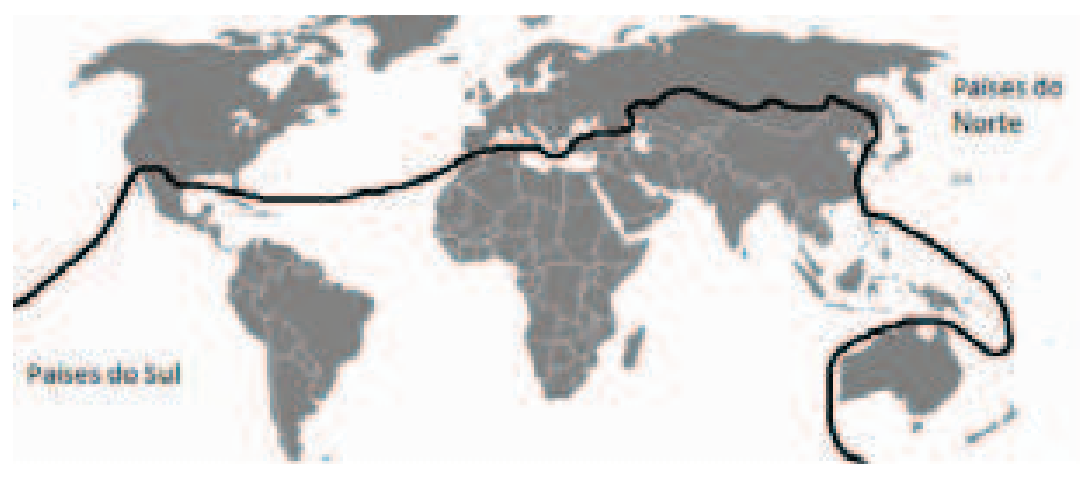

Figura 1: Mapa da divisão Norte-Sul.

Fonte: Elaboração própria a partir de mapa de WPHR (2010).

Sobrepondo-se o mapa da divisão Norte-Sul com o dos países cujo saldo líquido da ajuda internacional é positivo (figura 2) percebe-se uma correspondência quase perfeita entre esses e os denominados países do Sul. 


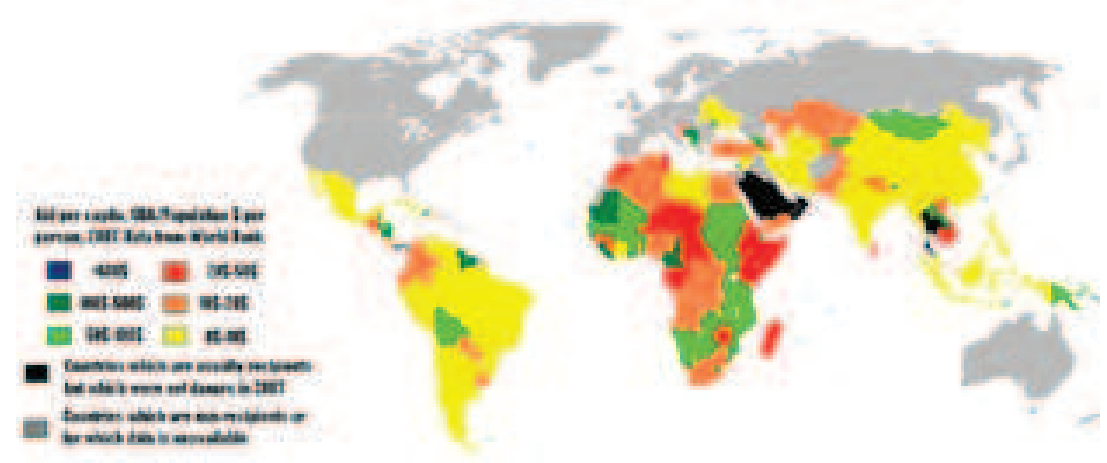

Figura 2: Mapa dos países cujo saldo líquido da ajuda internacional é positivo segundo dados sobre 0 desenvolvimento mundial do Banco Mundial para 0 ano de 2007 (cores conforme valores per capita percebidos).

Fonte: Tamara Saltzman (2011).

Em que pese a pertinência das contestações devida às diferenças que existem entre países reunidos em uma mesma categoria, no momento há ainda validade na classificação Norte-Sul uma vez que ela permite reunir sob um mesmo signo países com um grau de desenvolvimento semelhante que tem em comum o fato de grandes parcelas de suas populações não terem atingido níveis satisfatórios de bem-estar. Os países do Sul são, na melhor hipótese, emergentes, e por mais que se pretenda contestar a partir de argumentos relativos a avanços da última década a classificação de Brasil, China ou outros Estados em condições semelhantes, não haveria razões suficientes o bastante para classificá-los como desenvolvidos.

O Índice de Desenvolvimento Humano de 2010 permite aferir de forma clara que a esmagadora maioria dos países do Sul está bastante afastada dos índices dos países do Norte. Mesmo quando se analisa os supostamente mais débeis países do Nor- 
te em comparação a emergentes robustos do Sul, essa diferença se manifesta. Compare-se, por exemplo, os índices e posições de: Grécia (0,855 e 22a posição) e Brasil (0,699 e 73a posição); Portugal $\left(0,795\right.$ e 40a posição) e China ( 0,633 e $86^{\text {a }}$ posição) ou Lituânia (0,783 e 44a posição) e Índia (0,519 e 119a posição) (PNUD, 2011). Por mais que os primeiros países de cada par pudessem ter sua classificação contestada enquanto desenvolvidos, quando comparados com os países do Sul - mesmo com aqueles que estão entre os mais dinâmicos - uns e outros permanecem substancialmente distanciados.

Percebe-se, assim, que, por ora, ainda faz sentido a distinção Norte-Sul que dá nome à espécie de cooperação em análise. Tal constatação não permite concluir, contudo, que haja homogeneidade de desenvolvimento entre os países do Sul. Tal como aqueles do Norte, estes apresentam diferenças entre si que se perdem na categoria como de praxe acontece com toda categoria definida a partir de um esforço taxonômico. $\mathrm{O}$ preciosismo das minúcias do qual se abre mão para que as classificações sejam possíveis é geralmente compensado por uma possibilidade de sistematização e compreensão de fenômenos dentro de um marco mais abrangente.

O segundo questionamento conceitual se refere ao que se compreende por cooperação. Observações são feitas no sentido de que a amplitude temática das agendas de cooperação anunciadas (ex.: energia, comércio, pobreza, saúde, etc.) somada à pluralidade de dimensões (ex.: política, econômica, cultural, estratégica, etc.) que os países pretendem atingir dificultaria a definição do que configura a cooperação entre países do Sul. 
De acordo com tradicional dicionário da língua vernácula a palavra cooperação, em seu primeiro sentido, é o ato ou efeito de "operar ou obrar simultaneamente; trabalhar em comum; colaborar" (HOLANDA FERREIRA, 1986, p.407). Muito embora o segundo sentido apresentado seja o de auxílio, esse termo carrega uma carga semântica distinta no que diz respeito aos fluxos que se estabelecem entre os polos da relação. Com efeito, "auxílio" significa "ajuda; assistência" e, caso se recorra a mais significados "amparo, proteção, socorro, benefício" (p.204). Dessa forma, enquanto a cooperação parte da ideia de que os sujeitos da relação dialogam e constroem iniciativas em uma linha horizontal, vendo-se simultaneamente como contribuintes e beneficiários da relação, o auxílio pressupõe a hipossuficiência de uma das partes e a consequente superioridade da outra. Os fluxos de trocas e contribuições aparecem no sentido bilateral no primeiro caso e no sentido unilateral no segundo. Daí o traço da horizontalidade presente na CSS que a distingue do Auxílio ao Desenvolvimento aportado tradicionalmente por meio das relações Norte-Sul. Assim, menos importante do que a agenda específica da cooperação ou as dimensões pontuais que os países tem em mente quando a colocam em marcha, importa a situação relacional entre os agentes no que pertine a como eles se veem um em relação ao outro e o que esperam de suas relações. Nessa perspectiva a divisão por critérios objetivos entre países do Norte e do Sul passa a servir como referencial inicial para a análise das relações $S-S$, mas não se esgota nelas.

Esclarecidos alguns detalhes terminológicos, passa-se à reflexão sobre possíveis novidades desta articulação. 


\section{Uma relação com vários resultados}

Grande parte dos países - senão todos - que fazem parte desse Sul em movimento na CSS hodierna participaram, especialmente entre as décadas de 60 e 80, de uma concertação alternativa ao alinhamento a uma ou outra das potências da Guerra Fria. Chamado Movimento dos Não Alinhados, as ações desses países articulavam-se em torno da defesa da democratização das relações internacionais e da reivindicação de mudanças no sistema econômico mundial que se mantinha colonialista e imperialista (SEITENFUS, 2004). Nesse período, no âmbito da Assembleia Geral das Nações Unidas, os países que se tornavam independentes e assumiam um assento na organização passavam a demandar mudanças no sistema econômico mundial com vistas a que uma Nova Ordem Econômica Internacional prevalecesse.

Segundo análise de Lechini, foi nos anos setenta que "los países del Sur acuñaron la idea de la cooperación Sur-Sur para reforzar su capacidad de negociación con el Norte”. Entretanto essa cooperação teria fracassado por pressupor que todos os países subdesenvolvidos teriam mais coisas em comum do que realmente tinham (2007, p.271). A política monolítica, nesse contexto, apesar de unir os países sob um mesmo guarda-chuva para atuarem no cenário internacional, pouco correspondia, enquanto conjunto, às aspirações de cada um dos países individualmente. Daqui se extrai que o fato de as agendas de CSS atuais serem multisetoriais e tão variadas quanto variados são os estados cooperantes - como se referiu na seção anterior - poderia ser visto como um fator positivo. Isso porque, sendo uma cooperação mais fluída, com os agentes percebendo-se como parceiros e identificando 
pela medida do consenso setores e projetos específicos, aumenta-se o leque de possibilidades de parcerias, podendo essas ser articuladas à medida que houver interesse mútuo na relação e nos setores em que os interesses e capacidades mútuos forem identificados.

Outra questão interessante é que a CSS atual dá sinais de se articular não somente enquanto ação reativa a uma necessidade externa aos cooperantes como parecia fazer a cooperação Sul-Sul articulada segundo a análise de Lechini. De acordo com Rodrigues (2010, p.56), a concertação Sul-Sul oferece tanto a possibilidade de aumento de parceiros comerciais quanto uma possibilidade de maior interferência no contexto decisório do ambiente internacional. Essa visão do duplo potencial da cooperação, com um dos aspectos voltados para a cooperação em si (que pode não ser somente comercial, mas também técnica ou mesmo cultural), passível de ser proveitosa mesmo sem apresentar-se prima facie como mecanismo de inserção para obtenção de resultados frente a terceiros países, é um traço marcante na CSS da última década.

Neste sentido é ilustrativo o exemplo envolvendo grandes atores da CSS recente:

"Tanto o comércio entre a Índia, o Brasil e a África do Sul quanto com seus respectivos blocos de integração econômica aumentaram significativamente (e especialmente após a institucionalização do Fórum IBAS). O intercâmbio entre Índia e Mercosul mais do que duplicou entre 2001 e 2005, passando de menos de US $\$ 1$ bilhão para US\$2,3 bilhões. Além disso, o fluxo comercial entre a Índia e a África do Sul aumentou $133 \%$ no mesmo período, subindo de US\$1,3 bilhão para US\$ 3,1 bilhões. (RODRIGUES, 2010, p.63). 
Esta atuação no marco Sul-Sul recente apresenta marcados traços de pró-atividade por parte dos envolvidos. O caráter das manifestações, agora, deixa de ser apenas reivindicativo e passa também a ser propositivo, o que se reflete em ações e processos que não se exaurem nas declarações de intenções.

À medida em que protagonizam e propõem novos modelos e padrões de relações internacionais, a relação que se estabelece, além de produzir efeitos "para dentro" dos próprios países cooperantes (efeitos intra-relação), também redimensiona a capacidade de influência destes países nos fóruns e organismos internacionais, possibilitando a obtenção de resultados frente a terceiros países. Apesar desses resultados não serem necessariamente consequência direta da cooperação, é notável que algumas articulações foram bem-sucedidas.

O concerto que se alcançou com o G22 (hoje G20+) em torno das negociações da Rodada de Doha com relação aos produtos agrícolas bem exemplifica isso.

Avaliando a questão em relação ao grupo IBAS, Rodrigues (2010, p.62) pondera que, se as relações entre estes membros são de baixa complementaridade bilateral com relação a políticas setoriais conjuntas tomadas em uma longa trajetória, quando se trata de sua articulação tripartite, a baixa complementaridade bilateral é amenizada pela alta complementaridade multilateral que pode ser alcançada nas ações no sistema ONU e OMC, por exemplo.

Daí a pertinência da constatação de Cristina Soreanu Pecequilo quando pondera que convivem dois eixos dinâmicos na política externa brasileira no século XXI: o eixo horizontal (representado pela dimensão Sul-Sul) e o eixo vertical (representado pela dimensão 
Norte-Sul). Antes de excluírem-se mutuamente, parece que as articulações no eixo horizontal, além dos resultados per se obtidos, contribuem para a dinamização das ações e resultados que o país pode obter no eixo vertical. Nesse contexto a CSS pode figurar como facilitadora da geração de sinergias que levam à coordenação de forças multilaterais.

Percebe-se, assim, que, buscando uma alternativa às vias tradicionais de auxílio internacional construído no eixo Norte-Sul e aproveitando os vácuos de atuação não ocupados nessa frente, a CSS colocou em movimento experiências novas. Nisso há senso de oportunidade e os resultados que podem ser obtidos tem a potencialidade de serem maiores que os vazios de coordenação ocupados pelos países do Sul nessa forma de cooperação. As articulações entre estes países, vistas historicamente como periféricas e marginais, podem ter nesta nova formatação um potencial de sucesso. Estas experiências parecem revelar a emergência de um novo modelo de cooperação: partindo de um país marginal no sistema internacional para outro, também marginal, desconstroem a ideia de que as relações entre os países são jogos de soma zero, articulados sempre dentro de padrões dicotômicos doadores/receptores, contribuintes/beneficiários, e assim por diante.

\section{Propondo-se um conceito}

Passada praticamente uma década da nova dinâmica empreendida pela cooperação Sul-Sul (considerando-se como ponto decisivo deste cenário o seu incremento a partir das ações engendradas nos primeiros cinco anos da década passada), cabe propor uma diretriz 
geral que vá além das agendas individuais dos cooperantes, a partir da qual a cooperação possa ser pensada.

A partir das premissas que os próprios termos definem, a proposta deve necessariamente contemplar o caminho de mão dupla que se espera dos processos cooperativos, de modo que se possa considerar contribuições e benefícios para todos os envolvidos. Assim, parece interessante visualizar a cooperação Sul-Sul como uma articulação-via de regra-entre países emergentes que seja capaz de promover a ampliação das suas possibilidades, tanto individual - para cada um dos cooperantes - quanto coletivamente ${ }^{3}$. Em Diego Rodrigues já se poderia visualizar uma proposta neste sentido quando o autor refletia que "o multilateralismo Sul-Sul seria uma "saída viável" num momento de acentuado unilateralismo por parte da superpotência, os Estados Unidos pós-11 de setembro, ampliando os leques de possibilidades de cooperação e parcerias, tanto nas relações diretas entre os países quanto no fortalecimento das instituições internacionais" (2010, p.48).

Vale dizer, uma ação de CSS seria uma iniciativa engendrada entre países com características semelhantes de desenvolvimento que encerra em si a potencialidade de aumentar o leque de parcerias com outros países nos mais diferentes setores, além de oferecer a possibilidade de um aumento do poder desses países interferirem no desenho da agenda em foros internacionais. A questão-chave, portanto, é o aumento das alternativas à disposição de todos os polos envolvidos no

3 Este conceito traz grande inspiração da concepção de desenvolvimento tal qual concebida por Amartya Sen: desenvolvimento enquanto ampliação das possibilidades de escolha. 
processo cooperativo. Esse aumento de possibilidades pode gerar frutos que envolvam desde o aprendizado a partir de experiências compartilhadas e historicamente marginalizadas, abrindo alternativas ao determinismo decorrente de situações de debilidade que deixam pouco lugar para a eleição entre diferentes destinos futuros, até a abertura de margens de manobra e forças de pressão em foros internacionais.

Tal forma de visualizar a CSS - como instrumento para o incremento das alternativas nas mãos dos Estados - escapa da armadilha das visões lineares que reduzem tudo ao aspecto econômico e não permitem visualizar os benefícios de ordem técnica, política, cultural, etc. que em determinados casos estão mais de acordo com a multidimensionalidade das necessidades e recursos dos parceiros do Sul.

Em suma, propõe-se partir da compreensão da CSS não como um substituto para a articulação Norte-Sul e suas respectivas iniciativas, mas como um caminho possível para que os países do Sul aumentem suas alternativas de ação. É nesse sentido e dentro desse quadro que a CSS pode fazer alguma diferença. Ter isso presente afasta a antecipação de uma desilusão segura que viria caso se devotasse à CSS, por si só, a capacidade de resolução de uma situação de estrutural dependência.

\section{Definido setores, atores e instrumentos}

Conforme proposto, a CSS se define a partir dos termos da relação que é estabelecida. Assim, ela se encontra não nas doações de um doador a um receptor, mas na relação de países que são capazes de perceberem-se como sócios em um trabalho que se propõe a gerar 
benefícios mútuos. Assim, é fundamental que este estabelecimento se dê a partir do que uma e outra parte esperam e do que estes mesmos sujeitos tem condições e intenções de realizar.

Nesse sentido, parece importante estabelecer em cada iniciativa de CSS (a) as necessidades locais a partir de setores e atores definidos e (b) apresentar os instrumentos disponíveis por parte dos atores dispostos a cooperar.

Com relação às necessidades locais há que se considerar que as relações SS se dão em um marco com grande déficit de informação. Seria até despiciendo lembrar o quanto se desconhece, por exemplo, da história passada e recente de diversos países com os quais o Brasil tem estabelecido relações de cooperação. Sem uma compreensão das dinâmicas locais, muitas vezes estabelecidas ao longo de séculos de história, ações podem facilmente malograr em função, por exemplo, da desconsideração de atores fundamentais a um processo que ficaram excluídos do projeto de cooperação. Um bom exemplo disso poderia ser um trabalho para o reforço do sistema institucional judiciário haitiano ignorando as formas de solução de litígios institucionalizadas por líderes de comunidades locais no país. E, ainda, no processo de cooperação as iniciativas devem sempre trabalhar no sentido do empoderamento dos atores nos países nos quais se realizam. Este cuidado é fundamental para que essa forma de cooperação não incorra na mesma dinâmica verticalizada e dicotomizada (doador/receptor, etc.) estabelecida nas iniciativas Norte-Sul que retroalimentou, tantas vezes, a situação de dependência.

Ainda em relação à primeira necessidade é fundamental dialogar para definir os setores da possível cooperação sob pena de serem 
construídos projetos que se propõem a enfrentar situações que não representam espaços de interesse mútuo. Os setores de interesse por parte dos vários países do Sul são muitos (agricultura, infraestrutura, saúde, educação, justiça, segurança, etc.), mas nem todos podem ser promovidos a partir de qualquer articulação Sul-Sul. O importante aqui será o compartilhamento de ações que contemplem as melhores práticas. Na América Latina, por exemplo, há diversas experiências de sucesso, como a cubana na área da saúde; a brasileira no setor agrícola com agências como a EMBRAPA e suas pesquisas para o cultivo de legumes e verduras em regiões secas; a equatoriana que, no setor da educação conseguiu uma redução significativa do analfabetismo, entre outras.

Há que se considerar, portanto, a realidade e mesmo as potencialidades não exploradas na própria região.

Com relação aos instrumentos disponíveis por parte dos países dispostos a cooperar é importante que haja clareza quanto às possibilidades das partes envolvidas. Parece claro que a CSS não envolve - e não se propõe que envolva - ações com transferências de grande monta de recursos financeiros. A sua potencialidade está mais no compartilhamento de boas práticas e na capacitação de recursos humanos por meio de transferências de tecnologias e metodologias.

Das necessidades apontadas para construir-se a CSS resulta que o grande desafio para o estabelecimento de necessidades e definição de instrumentos é o diálogo. Neste sentido a CSS ainda é muito carente de espaços institucionalizados e de orçamento e projetos definidos para empreender ações de médio e longo prazos. Quanto menos os países individualmente investirem na institucionalização des- 
ses órgãos, mais vulnerável às políticas circunstanciais a CSS ficará, podendo, no limite, ser reflexo tão somente das inclinações pessoais dos governantes É forçoso reconhecer, todavia, que, por mais que não sejam as iniciativas Sul-Sul ancoradas em transferências de grandes montas de recursos financeiros, esses são absolutamente necessários em todas as etapas da cooperação, desde as designações dos órgãos internos aos países responsáveis pelo estabelecimento das relações horizontais até as negociações e implementações dos planos acordados.

\section{Um cenário de oportunidades e desafios}

$\mathrm{Na}$ CSS, entendida como a articulação entre países emergentes que seja capaz de promover a ampliação das suas possibilidades, a horizontalidade é traço distintivo. Nela o espírito da relação é cooperativo e pautado em um marco menos impositivo e discricionário do que as formulações anteriores. Nesse desenho, o perceber-se como parceiros facilita a promoção de ações que sejam mais condizentes com as necessidades dos cooperantes e cria melhores condições de adequação, mesmo durante seu curso, uma vez que o diálogo que as gera torna a dinâmica mais sensível aos contextos locais.

A horizontalidade também abre espaço para que sejam explorados setores frequentemente negligenciados em relações Norte-Sul. O compartilhamento de problemas semelhantes - isto é, a familiaridade com os problemas uns dos outros - pode ser, assim, uma porta para que sejam vislumbrados espaços de troca de melhores práticas pelos diversos países do Sul.

A CSS, além de espaço para encontrar alternativas capazes 
de melhorar a condição de vida das populações dos países do Sul, pode contribuir para melhor inserção internacional desses mesmos países. Diversos Estados lançam-se nessas parcerias para conquistar condições de participar mais ativamente da construção da agenda internacional. O caso brasileiro é exemplar nesse sentido, entretanto o desafio aqui é pensar mais estruturadamente a CSS, com fixação de objetivos mais consistentes a médio e longo prazos.

Nessa linha de raciocínio, é importante ressaltar também as dificuldades que a CSS enfrenta. De fato seria leviano pretender que a CSS fosse o espaço ideal de cooperação, pleno de oportunidades e sem limitações. Ao contrário, os limites que aparecem em relação à CSS são diversos e podem aproximadamente ser reunidos nos seguintes aspectos :

a) Desconhecimento entre os parceiros no que diz respeito à sua história, cultura, tradições, etc., dificultando a abertura de diálogos;

b) Maior vulnerabilidade aos movimentos globais, que podem levar a uma rápida desarticulação da cooperação externa caso haja a percepção da necessidade de tratar de alguns problemas como assuntos unicamente domésticos (ex.: violência e migrações);

c) Necessidade de articulação entre Estados com diversas deficiências de recursos humanos qualificados para a formulação, coordenação, gestão e execução dos projetos de cooperação.

d) Risco de sobreposição de agendas por parte da potencia mundial de forma a securitizar temas que poderiam ser abordados no âmbito da CSS; 
e) Dificuldade na criação e manutenção de sistemas de informação sobre setores e atores potenciais para a cooperação; f) Ausência de mensuração de impactos e avaliação dos resultados das iniciativas em curso.

Alguns desses desafios precisam ser resolvidos para que a própria CSS seja possível, como é o caso do provimento de recursos humanos aptos a sistematizar e implementar os processos cooperativos. Outros, como o conhecimento da história, cultura e tradições entre os parceiros podem ser enfrentados paulatina e continuamente e se reforçarão à medida em que a própria CSS tiver curso (ex.: cooperação entre centros universitários que podem construir pesquisas em torno de objetos específicos - ao mesmo tempo que unem-se esforços para a construção científica, geram-se motivação e possibilidades para a aproximação das práticas e culturas de ambos).

\section{CONSIDERAÇÕES FINAIS}

A partir da análise do processo em curso podem-se ler alguns contornos que vem assumindo essa dinâmica cooperativa entre países do Sul e, considerando-os, pode-se elaborar um quadro mais sistemático do fenômeno e das oportunidades e desafios que a sua implementação enfrenta. Os parágrafos que seguem sintetizam as conclusões a que se chegou com este trabalho.

Com relação à consistência do termo "cooperação Sul-Sul" sustentou-se que, pelas características aproximadamente similares que reúnem, por enquanto e para este contexto ainda é válida a divisão entre países do Norte e países do Sul. Ainda, no que se refere à 
questão terminológica, percebeu-se que a palavra cooperação (em detrimento do uso de outras como auxílio ou ajuda) adequa-se melhor ao processo em curso por servir para definir uma relação em que todas as partes envolvidas percebem-se como contribuintes e beneficiárias dos projetos.

Essa duplicidade não está presente somente em relação aos papéis dos atores mas, também, nos resultados que vislumbram possíveis por meio da CSS. Assim, além de se apresentar como mecanismo de inserção para obtenção de resultados frente a terceiros países, os cooperantes percebem-na como uma relação capaz de ser intrinsecamente proveitosa em função dos ganhos comerciais, culturais, técnicos e de melhores práticas que ela pode gerar.

Propôs-se, a partir desse desenho inicial de atores, expectativas e instrumentos, uma definição para a CSS como uma articulação entre países emergentes que seja capaz de promover a ampliação das suas possibilidades. Tal definição reforça dois aspectos que devem estar no hard core da Cooperação Sul-Sul: a horizontalidade e a ampliação de alternativas à disposição dos cooperantes (tanto para desafios internos dos cooperantes quanto para desafios das relações mantidas com terceiros países).

Proposta uma definição conceitual, para que seja capaz de sustentar-se como uma relação horizontal, como um verdadeiro caminho de mão dupla, é necessário que as partes sistematizem a sua construção, desenvolvimento e avaliação, envolvendo e empoderando atores, definindo de maneira consciente os setores-alvo e visando aproveitar os melhores recursos à disposição de cada um dos cooperantes. Quanto mais clareza em relação a atores, setores e instru- 
mentos houver, melhores resultados poderão ser conseguidos e menos expectativas desproporcionais serão construídas.

A CSS, sem querer substituir a cooperação articulada na matriz Norte-Sul, tem diversos campos inexplorados de cooperação para desbravar. A preocupação com problemas peculiares aos países do Sul - e, portanto, já fora da gramática de soluções dos países desenvolvidos - e a familiaridade com os gargalos semelhantes que enfrentam, abrem um grande leque de oportunidades a serem exploradas na via horizontal. Essas oportunidades não aparecem em um contexto desprovido de limitações que, em relação à CSS, são significativas. Algumas delas, se não forem superadas, impedem o próprio processo de se desenvolver; já outras podem, no próprio curso dos projetos de CSS, contribuir para a sua superação.

\section{REFERÊNCIAS}

HOLANDA FERREIRA, Aurélio Buarque. (1986) Novo Dicionário Aurélio da Lingua Portuguesa. 2a. Ed. Rio de Janeiro: Nova Fronteira, 1986.p. 204 e p. 472.

LECHINI, Gladys. (2007) IBSA: una opción de cooperación Sur-Sur. In.: Del Sur hacia el Norte: Economía política del orden económico internacional emergente. Giron, Alicia; Correa, Eugenia (orgs.). Buenos Aires: CLACSO, 2007. Disponível em: < http://bibliotecavirtual. clacso.org.ar/ar/libros/sur sur/giron_correa/25Lechini.pdf >. Acesso em: 03.jul.2011.

- ¿La cooperación Sur-Sur es aún posible? El caso de las estrategias de Brasil y los impulsos de Argentina hacia los estados de Africa y la nueva Sudáfrica. In.: Política y movimientos sociales en un mundo hegemónico. 
Lecciones desde África, Asia y América Latina. Boron, Atilio A.; Lechini, Gladys (orgs.). Buenos Aires: CLACSO, 2006. Disponível em <http:// bibliotecavirtual.clacso.org.ar/ar/libros/sursur/politica/PIVCuno.pdf $>$. Acesso em: 03.jul.2011.

WPHR - World Poverty and Human Rights. (2010) North-South division. Disponível em: <http://wphr.org/wpcontent/uploads/2010/04/ North_South_divide_svg1.png>.Acesso em: 07.jul.2011.

PECEQUILO, Cristina Soreanu. (2008) A Politica Externa do Brasil no Século XXI: os eixos combinados de cooperação horizontal e vertical. Revista Brasileira de Política Internacional-RBPI, Ano 51, No 2, 2008, pp. 136153.

PNUD - Programa das Nações Unidas para o Desenvolvimento. (2011). Ranking do IDH 2010. Disponível em: < http://www.pnud.org.br/ pobreza_desigualdade/reportagens/index.php?id01=3600\&lay=pde $>$. Acesso em: 07.jul.2011.

RODRIGUES, Diego de Freitas. (2010) Cooperação horizontal SulSul: arranjos de concertação política entre a Índia, o Brasil e a África do Sul. Revista Brasileira de Política Internacional-RBPI, Ano 53, No 1, 2010, pp. 45-66.

SALTZMAN, Tamara. (2011). Aid Conditionality. In.: WPHR - World Poverty and Human Rights. Disponível em: <http://wphr.org/2011/ tamarasaltzman/aid-conditionality/>. Acesso em: 07.jul.2011.

SEITENFUS, Ricardo. (2004) Relações Internacionais. Barueri, SP: Manole, 2004.

SOARES DE LIMA,Maria Regina.(2005) A política externa brasileira e os desafios da cooperação Sul-Sul. Revista Brasileira de Política InternacionalRBPI, Ano 48, No 1,2005, pp. 24-59. 
ZULUAGA NIETO, Jaime. (2006) Una Tricontinental del conocimiento: un espacio para la cooperación Sur-Sur. In.: Política y movimientos sociales en un mundo hegemónico. Lecciones desde África, Asia y América Latina. Boron, Atilio A.; Lechini, Gladys (orgs.). Buenos Aires: CLACSO, 2006. Disponível em <http://bibliotecavirtual.clacso.org.ar/ ar/libros/sursur/politic a/PIVCcuatro.pdf>. Acesso em: 03.jul.2011. 